\title{
PRESENÇA DE ANALITOS QUÍMICOS E MICROSCÓPICOS NA URINA E SUA RELAÇÃO COM INFECÇÃO URINÁRIA
}

\author{
PRESENCE OF CHEMICAL AND MICROSCOPIC \\ ANALYTES IN URINE AND ITS RELATIONSHIP \\ WITH URINARY TRACT INFECTION
}

\author{
Lenir Alves Bortolotto', Denise Michelle Indras², \\ Claudinei Mesquita da Silva ${ }^{3}$, Leyde Daiane de Peder ${ }^{4}$
}

\section{RESUMO}

Microrganismos podem atingir o trato urinário pela via ascendente ou sangue levando a graves infecções e custos para o sistema público de saúde, sendo assim é imprescindível um diagnóstico rápido para o tratamento adequado e diminuição de gastos. A urocultura é padrão ouro neste processo pela sua precisão, porém, é lento e de custo elevado, sendo necessários testes adicionais com tiras reativas e microscópicos durante a urinálise, os quais são mais rápidos e de custo mais baixo e que sugerem casos negativos ou presença de bactérias. O presente trabalho teve como objetivo correlacionar presença de analitos químicos e microscópicos com infecção urinária, tendo como base a urocultura, a partir da análise de 1576 laudos de pacientes que realizaram exame de urina em um laboratório particular de Cascavel-PR entre 2012 e 2015. Foram calculados os parâmetros de validação para nitrito positivo e aumento de leucócitos tendo como base urocultura positiva, nos quais foi verificada sensibilidade de $32,4 \%$ e 83,6\%, especificidade e VPP de 100\% para ambos, VPN de $88,7 \%$ e $97,0 \%$ e eficiência de $89,3 \%$ e 97,3\%, respectivamente. Assim, todos os parâmetros demonstraram que o diagnóstico mais adequado para infecções urinárias é a determinação do aumento do número de leucócitos e não o teste de nitrito.

Descritores: Urocultura; Urinálise; Infecção do Trato Urinário; Bactérias.

\begin{abstract}
Microorganisms can reach the urinary tract by ascending or via blood leading to severe infections and cost to the public health system, so it's essential a rapid diagnosis for proper treatment and cost-cutting. The urine culture is the gold standard in this process owing accuracy, however, is slow and expensive, requiring additional testing with reactive and microscopic strips for urinalysis, which are faster and lower cost and suggest negative cases or presence bacteria. This study aimed to correlate the presence of chemical and microscopic analytes with urinary tract infection, based on urine culture, from the analysis of 1576 reports of patients who underwent urinalysis in a particular laboratory Cascavel - PR between 2012 and 2015. Validation parameters were calculated for positive nitrite and leukocyte increase based on positive urine culture, which was observed in $32.4 \%$ sensitivity and $83.6 \%$ specificity and $100 \%$ PPV for both VPN $88.7 \%$ and $97.0 \%$ efficiency and a $89.3 \%$ and $97.3 \%$, respectively. Thus, all parameters showed that more appropriate diagnosis of urinary tract infections is the determination of the increase in the number of leukocytes and no nitrite test.
\end{abstract}

${ }^{1}$ Graduada em Farmácia pelo Centro Universitário da Fundação Assis Gurgacz (FAG), Cascavel, PR, Brasil.

\section{${ }^{2}$ Especialista em Análises Clínicas pela Universidade Estadual do Oeste do Paraná (UNIOESTE), Cascavel, PR, Brasil.}

${ }^{3}$ Mestre em Biologia Molecular pela Universidade Federal de São Paulo (UNIFESP), São Paulo, SP, Brasil.

${ }^{4}$ Mestre em Ciências pela
Universidade Federal de São
Paulo-Escola Paulista de
Medicina, (UNIFESP/EPM),
São Paulo, SP, Brasil.

${ }^{4}$ Mestre em Ciências pela Paulo-Escola Paulista de São Paulo, SP, Brasil.

Descriptors: Urine Culture; Urinalysis; Urinary Tract Infection; Bacteria. 


\section{Introdução}

As infecções do trato urinário (ITU) são as mais comuns nas clínicas médicas, são caracterizadas como a invasão microbiana de qualquer órgão do trato urinário desde a uretra até os rins ${ }^{1}$. 0 processo infeccioso pode atingir o rim, a pelve renal, os ureteres, a bexiga e a uretra, além das estruturas adjacentes, incluindo próstata e epidídimo, existindo possibilidades de agravamento na dependência do estado geral do paciente e da sua idade, merecendo, assim, grande atenção em pesquisas e estudos nas ciências médicas.

Normalmente, no aparelho urinário, não existem quaisquer microrganismos, contrariamente ao que se passa com outros aparelhos em comunicação com o meio exterior. Os estudos sobre as origens das ITU variam de acordo com 0 gênero, idade e estado geral do paciente, aquisição hospitalar ou comunitária e uso de antimicrobianos. Na vida adulta, a incidência de ITU aumenta, apresentando maior prevalência no gênero feminino, com picos de maior acometimento no início da atividade sexual ou relacionado a ela, também durante a gestação ou na menopausa². Estudos epidemiológicos estimam que, anualmente, $10 \%$ das mulheres são diagnosticadas com cistite e $60 \%$ têm pelo menos um episódio de ITU ao longo da vida ${ }^{3}$. As enfermidades do trato urinário se destacam não só pela sua frequência como também pela possibilidade de causarem complicações graves, como insuficiência renal e septicemia ${ }^{4}$. Correspondem a infecções de grande destaque em pacientes hospitalizados e podem levar a grandes custos e aumento da estadia hospitalar ${ }^{5}$.

Vários microrganismos tem sido detectados como agentes etiológicos das ITUs, no entanto, Escherichia coli e Staphylococcus saprophyticus estão envolvidos em cerca de $80 \%$ das infecções urinárias não complicadas encontradas na população, particularmente em mulheres com menos de 50 anos de idade.Além dessas bactérias, Proteus mirabilis, Enterococcus faecalis e Klebsiella pneumoniae também apresentam grande prevalência ${ }^{6}$. Para a confirmação da infecção urinária exames como urocultura são comumente utilizados, sendo esta metodologia considerada padrão-ouro para o diagnóstico?

A análise microscópica, assim como a análise química do sedimento urinário fornecem importantes subsídios a respeito das ITUs e a presença de qualquer alteração é sugestiva, mas não confirmatória para a mesma, além de fornecer informações sobre patologias extra-renais. As fitas reagentes, análises químicas, são usadas especialmente na triagem de casos agudos suspeitos de ITU, pela sua simplicidade, baixo custo e facilidade na obtenção de resultado e são considerados como exame de rotina ${ }^{8}$.

Embora a urocultura seja um exame imprescindível para o diagnóstico de uma infecção urinária, esse método apresenta desvantagens, como a demora no tempo de realização e 0 alto custo ${ }^{7}$. Por esse motivo, esforços têm sido despendidos para se obter um teste de triagem que traga resultados baratos, confiáveis e rápidos. Desta forma, 0 presente trabalho teve como objetivo correlacionar a presença de nitrito positivo, um analito químico, assim como, 0 aumento de leucócitos, uma análise microscópica, com infecção urinária, tendo como base a urocultura positiva.

\section{Metodologia}

Para a execução do presente trabalho, foi realizada a análise de laudos eletrônicos presentes no sistema SIAC (Sistema Integrado de Análises Clínicas) de um laboratório particular de Cascavel-PR, relativos a pacientes submetidos a exames de urina entre junho de 2012 e junho de 2015. O laboratório realiza exames para hospitais de Cascavel e região, da rede privada, de convênios e do Sistema Único de Saúde.

Dos laudos foram extraídos os resultados relativos à análise química (nitrito), análise microscópica (número de leucócitos) e análise microbiológica (positividade/negatividade e bactérias encontradas na urocultura).

Os exames foram realizados pelo laboratório com amostras adquiridas por coleta de urina de jato médio de micção espontânea. Os exames químicos foram realizados com tira reagente UROFITA 10 DLU (MACHEREY-NAGEL). A definição de positividade ou negatividade foi realizada por comparação com os padrões da tira pelo equipamento LabUReader (ALERE). Para os exames microscópicos, utilizou-se a técnica qualitativa, no qual define-se a quantidade média de elementos por campo de visualização de grande aumento (400x) em dez campos.

Para a urocultura, o laboratório utilizou o meio Ágar CLED, com semeadura por esgotamento e estriamento, incubados por 48 horas. As bactérias foram definidas pelo crescimento de pelo menos $10^{5}$ unidades formadoras de colônias por $\mathrm{mL}$ de urina (100.000 ufc/mL) colhida em jato médio e de maneira asséptica. Para pacientes idosos, infecções crônicas e na utilização de antimicrobianos, foi considerado crescimento bacteriano igual ou superior a $10^{4}$ colônias (10.000 ufc/ml) ${ }^{9}$. 
Os dados obtidos foram tabulados no programa Microsoft Office Exce $^{\circledR}$ e os resultados foram classificados como verdadeiros positivos (VP), verdadeiros negativos (VN), falsos positivos (FP) e falsos negativos (FN). Foram determinados os parâmetros para validação das determinações (presença de nitrito e aumento de leucócitos) em relação à urocultura positiva, a qual é considerada técnica padrão para determinação de infecção urinária, por meio de cálculos de sensibilidade (VPNP+FN), especificidade (VN/VN+FP), eficiência (VP+VN/VP+VN+FP+FN), valor preditivo positivo (VPP) (VP/VP+FP); valor preditivo negativo (VPN) (VN/VN+FN).

Foi também utilizado o teste de Qui quadrado $\left(\mathrm{x}^{2}\right)$ em nível de significância de $5 \%$ com resultados considerados estatisticamente significativos para $p \leq 0,05$ para análise e estudo sobre a associação entre variáveis. Aanálise estatística foi realizada através do software Bioestat ${ }^{\circledR} 2.0$.

O projeto foi aprovado pelo Comitê de Ética em Pesquisa com Seres Humanos da Faculdade Assis Gurgacz sob parecer 857.540 de 08/10/2014, após carta de concordância emitida pelo responsável pelo laboratório.

\section{Resultados e Discussão}

Foram analisados 1576 laudos de urocultura de pacientes diferentes no período compreendido entre junho de 2012 a junho de 2015 obtendo-se como resultados os dados descritos na Figura 1.

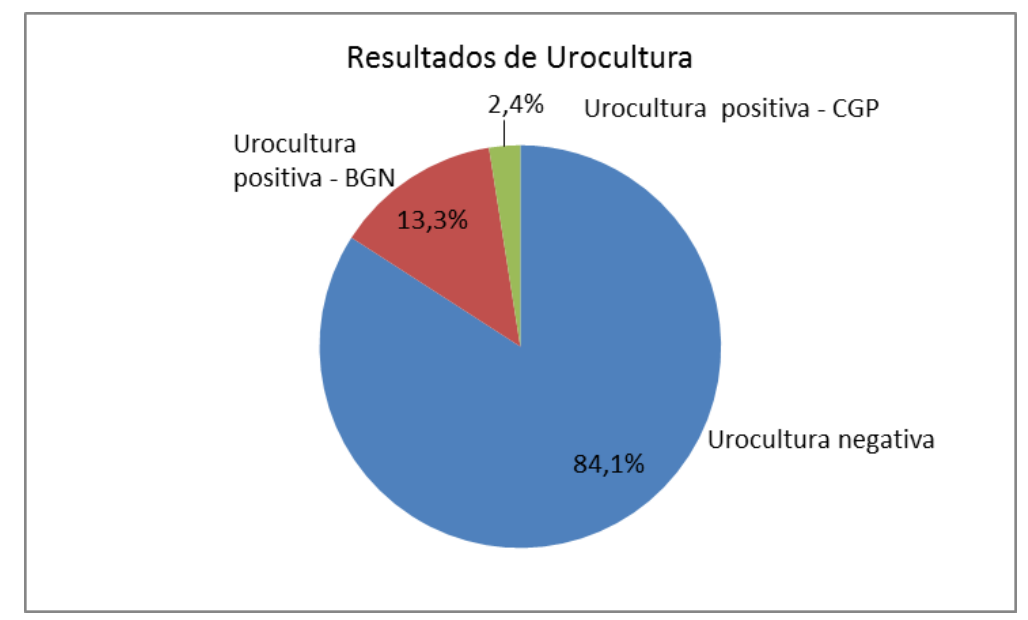

Figura 1 - Resultados de urocultura coletados de laudos de pacientes atendidos por um laboratório privado. Cascavel-PR, 2012 a 2015.

Verificou-se uma prevalência de infecções urinárias de 15,7\% nos laudos analisados, sendo que 13,3\% das infecções foram causadas por bacilos Gram negativos (BGN). Em outras pesquisas realizadas no Brasil, os dados coletados demonstraram igualdade $15,7 \%^{10}$, semelhança, $15,0 \%{ }^{11}, 16,4 \%^{12}$, e percentuais ligeiramente maiores, como $22,6 \%{ }^{13}$ e $22,8 \%{ }^{14}$.

De todas as uroculturas positivas (250), em 211 , (84,4\%) foi detectada a presença de BGN e em $39(15,6 \%)$ cocos gram positivos (CGP). Este resultado foi um pouco superior para as BGN daqueles apurados por Muller et al (2008) e Ramos et al (2006), onde a frequência de isolamento de BGN foi de 70-75\% e inferior para as CGP, onde estes pesquisadores encontraram 25-30\%, sugerindo que estes microrganismos vem crescendo como causadores de ITUs.

Em análise dos casos de urocultura positiva, verificou-se a frequência das principais bactérias encontradas, bem como, sua relação quanto à conversão de nitrato em nitrito e o aumento de leucócitos, conforme escrito na Tabela 1.

Os testes que utilizam tiras reagentes e como consequência a determinação de nitrito detectam significativamente mais infecções por bactérias Gram negativas do que por espécies Gram positivas, já que o teste de nitrito pode não revelar a presença de bactérias Gram positivas em muitos casos ${ }^{15}$. A conversão de nitrato em nitrito na urina por cocos Gram positivos ainda não está bem estabelecida, mas estudos tem demonstrado essa ocorrência ${ }^{16}$. 
Tabela 1. Descrição e frequência dos BGN e CGP relacionados à frequência de conversão de nitrato a nitrito e aumento de leucócitos. Laboratório privado, Cascavel-PR, 2012 a 2015.

\begin{tabular}{c|c|c|c|c|c}
\hline Bactérias & $\begin{array}{c}\text { Frequência no } \\
\text { total de exames } \\
\text { analisados } \\
\mathbf{( n = 1 5 7 6 )}\end{array}$ & $\begin{array}{c}\text { Frequência } \\
\text { com urocultura } \\
\text { positiva (n=250) }\end{array}$ & $\begin{array}{c}\text { Nitrito } \\
\text { positivo } \\
\mathbf{n}(\%)\end{array}$ & $\begin{array}{c}\text { Mais de 5 } \\
\text { leucócitos }\end{array}$ & Valor de p \\
\hline Escherichia coli & $177(11,2 \%)$ & $70,8 \%$ & $60(33,9)$ & $142(80,2)$ & $<0,0001$ \\
\hline Klebsiela pneumoniae & $26(1,6 \%)$ & $10,4 \%$ & $9(34,6)$ & $23(88,5)$ & $<0,0001$ \\
\hline Staphylococcus aureus & $20(1,3 \%)$ & $8 \%$ & $5(41,4)$ & $19(95,0)$ & $<0,0001$ \\
\hline S. saprophyticus & $11(0,7 \%)$ & $4,4 \%$ & $0(0,0)$ & $11(100,0)$ & $<0,0001$ \\
\hline Enterococcus faecalis & $8(05 \%)$ & $3,2 \%$ & $3(37,5)$ & $6(75,0)$ & 0.0114 \\
\hline Proteus mirabilis & $5(0,3 \%)$ & $2 \%$ & $4(80,0)$ & $4(80,0)$ & $>0.9999$ \\
\hline Enterobacter cloacae & $2(0,1 \%)$ & $0,8 \%$ & $0(0,0)$ & $2(100,0)$ & $<0,0001$ \\
\hline Pseudomonas aeruginosa & $1(0,1 \%)$ & $0,4 \%$ & $0(0,0)$ & $1(100,0)$ & $<0,0001$ \\
\hline Total & $250(15,9 \%)$ & $100 \%$ & 81 & 208 & \\
\hline
\end{tabular}

A maioria das infecções urinárias é causada por BGN, sendo que, o microrganismo invasor mais comum é a Escherichia coli, detectada em cerca de $70 \%$ a $90 \%$ das infecções bacterianas agudas não complicadas das vias urinárias $^{17-20}$, o que foi também visualizado no presente estudo. No entanto, casos de CGP, como Staphylococcus saprophyticus, podem ser responsáveis por $10 \%$ a $20 \%$ dos casos em mulheres jovens adultas, sendo descrito como a segunda causa mais frequente de ITU nessas pacientes, enquanto que outras bactérias Gram positivas são relativamente raras, podendo incluir estreptococos dos grupos $B$ e $D^{21}$.

Nas infecções complicadas, na presença de anormalidade anatômica ou cateterização crônica, o espectro de bactérias infectantes é maior do que nos casos não complicados. Verifica-se quase sempre também a presença E. coli, porém muitas espécies de outros bastonetes Gram negativos, por exemplo, Klebsiella, Proteus, Enterobacter e Pseudomonas, e Gram positivos, como, enterococcos e estafilococos, também são comuns. Em muitos casos são identificadas duas ou mais espécies, e as bactérias são quase sempre resistentes aos agentes antimicrobianos administrados ${ }^{17}$.

A infecção por BGN e CGP é dez a vinte vezes mais frequente em mulheres do que em homens. Tal fato se deve à formação anatômica da genitália externa, assim como ao comprimento da uretra feminina, que favorece a ascensão das bactérias que colonizam o intróito vaginal para o interior da bexiga ${ }^{22}$.

Em relação aos CGP, o presente estudo detectou que a bactéria mais recorrente (8\%) foi Staphylococcus aureus (20 casos), seguida por Staphyloccocus saprophyticus (11 casos/4,4\%), o que mostrou resultados diversos dos autores evidenciados, talvez pelo fato de que neste estudo a análise dos exames não fora direcionado com atenção especial as ITUs detectadas em mulheres jovens adultas com vida sexualmente ativa e sim de modo genérico.

O diagnóstico de uma infecção do trato urinário é geralmente feito em bases clínicas e laboratoriais ${ }^{23}$. Aurocultura é 0 exame mais importante para o diagnóstico de uma infecção urinária, pois não apenas indica a ocorrência de multiplicação bacteriana no trato urinário, mas também permite 0 isolamento do agente causal e 0 estudo de sua sensibilidade frente aos antimicrobianos. Habitualmente, considera-se positiva a presença de número igual ou superior a cem mil $(>105)$ unidades formadoras de colônias bacterianas por mililitro de urina adequadamente coletada. Entretanto esse método apresenta desvantagens, como o longo período de tempo exigido no diagnóstico e ter consequente elevado custo ${ }^{24}$.

Diversas metodologias de triagem para detecção da bacteriúria encontram-se disponíveis e constituem um atrativo pela sua rapidez, praticidade e economia na predição das ITU. Por isso, esforços têm sido realizados para selecionar um teste de triagem padrão, que possibilite a análise de várias amostras de urina, concomitantemente.

$O$ teste das tiras reagentes para bacteriúria (teste de Greiss) fundamenta-se na medida indireta de bactérias redutoras do nitrato a nitrito. Em BGN, incluindo $E$. coli, essa conversão ocorre em 99\%-100\% dos casos. Já para CGP, ainda não está bem estabelecida, dependendo muito da espécie bacteriana ${ }^{25}$. Foi descrito que a utilidade desse teste está restrita às enterobactérias, para as quais o resultado é positivo, já que as CGPs, raramente produzem enzimas de redução de nitrato ${ }^{26}$. 
Os estudos elaborados pelos autores anteriormente citados divergem do que fora constatado no presente trabalho, onde verificou-se que dos 250 casos de urocultura positiva submetidos ao testes de fita reativa, (211 BGN) e (39 CGP) apenas 81 casos detectaram a presença de nitrito, concordando com a afirmação de Yoshida et al (2006), visto que, neste trabalho detectou-se casos de nitrito positivo para CGP. Verificou-se também quantidade estatisticamente significativa $(p<0,0001)$ maior de casos de infecções bacterianas com aumento de leucócitos quando comparado à conversão de nitrato a nitrito (Tabela 1).

A Tabela 2 mostra a associação entre a análise microbiológica (resultado das uroculturas), a análise química (nitrito em tiras reativas) e as análises microscópicas (número de leucócitos) observados no presente estudo.

Tabela 2 - Associação entre urocultura, nitrito e leucócitos. Laboratório privado, Cascavel-PR, 2012 a 2015.

\begin{tabular}{c|c|c|c|c}
\hline Urocultura & Nitrito positivo & Nitrito negativo & $\begin{array}{c}\text { Superior a 5 } \\
\text { leucócitos }\end{array}$ & $\begin{array}{c}\text { Inferior ou } \\
\text { igual a 5 } \\
\text { leucócitos }\end{array}$ \\
\hline Positiva & $81(\mathrm{VP})$ & $169(\mathrm{FN})$ & $208(\mathrm{VP})$ & $42(\mathrm{FN})$ \\
\hline Negativa & $0(\mathrm{FP})$ & $1326(\mathrm{VN})$ & $0(\mathrm{FP})$ & $1326(\mathrm{VN})$ \\
\hline Total & 81 & 1495 & 208 & 1368 \\
\hline
\end{tabular}

VP: Verdadeiros Positivos; FN: Falsos Negativos; FP: Falsos Positivos; VP: Verdadeiro Negativo.

A especificidade é definida pela porcentagem de resultados negativos apurados entre indivíduos não doentes, ou seja, a proporção dos verdadeiros negativos, já a sensibilidade é definida pela percentagem de resultados positivos entre os indivíduos doentes, a proporção de verdadeiros positivos ${ }^{27}$. Um teste $100 \%$ sensivel não apresentaria falsos negativos e um teste $100 \%$ específico não apresentaria falsos positivos. Infelizmente, não há testes $100 \%$ sensíveis nem $100 \%$ específicos ${ }^{28}$.

A partir dos resultados obtidos com a determinação de nitrito por meio da Urofita, chegou-se aos seguintes valores: sensibilidade de $32,4 \%$, especificidade de $100 \%$, valor preditivo positivo de $100 \%$, valor preditivo negativo de $88,7 \%$ e eficiência de 89,3\%, para nitrito em relação à urocultura.

A especificidade da prova de nitrito na urina pelas tiras reagentes foi elevada em todas as pesquisas analisadas ${ }^{28-30}$, inclusive neste estudo, representando, portanto, que a probabilidade do teste ser negativo, determinando-se que os pacientes examinados não são portadores da doença é muito alta, o que representa os casos negativos coincidentes entre as provas de nitrito e urocultura. Todavia, a sensibilidade revelou-se muito baixa na maioria das pesquisas, significando que é baixa a probabilidade da prova de nitrito ser positiva nos casos de ITU bacteriana confirmada pela urocultura.

Para o VPP, isto é, a probabilidade do paciente estar realmente doente quando o resultado de nitrito pela Urofita é positivo, é de 100,0\% neste estudo, levando a uma predição de falso positivo (FP) de 0,0\%, o que corrobora com 0 descrito por Sobestiansky et al (2009), para o VPN que é a probabilidade de o paciente não estar doente quando 0 resultado é negativo, o valor foi de $88,7 \%$.

O presente estudo corrobora com o afirmado por Richard (2009), pois dentre os casos positivos de BGN e CGP (250) em apenas 81 foi detectada a presença de nitrito, especialmente nas BGN ( $E$. coli), discordando, no entanto, quanto as CGP, já que foi encontrado resultado de nitrito positivo em 4 casos de infecção por Staphylococcus saprophyticus.

Outros fatores também podem influenciar no resultado negativo de nitrito nos testes de Urofitas, como quando 0 tempo de contato entre a bactéria e o nitrato é pequeno. Resultado falso negativo pode ocorrer quando detectada terapia antibiótica, ou por concentração muito baixa de nitrato na urina, que pode ser ocasionado por dietas pobres em nitratos ou por alta diluição da amostra por diurese. Já o resultado falso positivo pode ocorrer pela presença de corantes de uso diagnóstico ou terapêutico ${ }^{26}$. Entretanto, estes fatores, não são suficientes para justificar a elevada frequência de falsos negativos, constatada neste estudo.

Das 250 amostras com urocultura positiva, observados no presente estudo, 208 apresentaram mais de 5 leucócitos por campo, conforme descrito na Tabela 2. A partir dos números encontrados nas uroculturas em associação com a quantificação de leucócitos em exame microscópico, obteve-se os seguintes resultados: sensibilidade de $83,2 \%$, especificidade de $100,0 \%$, valor preditivo positivo de $100,0 \%$, valor preditivo negativo $96,9 \%$ e eficiência de $97,3 \%$, para leucócitos em relação à urocultura. 
Até cinco leucócitos por campo de grande aumento (400x) é considerado como urina normal, muito embora diversos sejam os valores descritos na literatura. Com $12 \mathrm{~mm}$ de diâmetro, o leucócito geralmente encontrado no sedimento urinário é o neutrófilo que se demonstra particularmente acumulado ${ }^{31,32}$.

A análise de urina a fim de realizar avaliação de leucocitúria e bacteriúria pode ser realizada por meio de técnicas convencionais, com urina centrifugada. Oexame microscópico é realizado após a centrifugação da urina com possibilidades de encontrar leucocitúria consideradas anormais em contagens superiores a 10.000 leucócitos $/ \mathrm{mL}$ independentemente da morfologia destes leucócitos ${ }^{33}$.

Este estudo corrobora com os resultados obtidos nas pesquisas feitas pelos autores Richard (2009) e Ávila (2011), vez que, dos casos detectados de ITU (250) em 208 foram detectados mais de cinco leucócitos por campo, sendo tal análise um ótimo indicativo da presença de ITU nos pacientes examinados.

\section{Considerações Finais}

Embora tenha se verificado especificidade de 100,0\%, VPP de 100,0\%, VPN de 88,7\% e eficiência de 89,3\% para nitrito, a sensibilidade foi extremamente baixa, isto é, $32,4 \%$. Já para aumento de leucócitos, todos os parâmetros apresentaram-se mais elevados, verificando-se especificidade e VPP de 100,0\%, VPN de 96,9\%, eficiência de 97,3\% e sensibilidade de $83,2 \%$. Aliado a esses resultados, verificou-se que um maior número de bactérias apresentou aumento de leucócitos, quando comparado à produção de nitrito, o que comprova ser o aumento de leucócitos um exame mais eficiente do que a produção de nitrito para a detecção de infecções urinárias.

\section{Agradecimentos}

Os autores agradecem ao Laboratório Biovel de Análises e Pesquisas Clínicas, por todos os dados fornecidos para a presente pesquisa.

\section{Referências}

1. Marangoni DV. Moreira BM. Infecções do trato urinário. Doenças infecciosas: conduta terapêutica. Rio de Janeiro. Guanabara Koogan. 1994.

2. Rieger A, Ferrugem F, Horta G, et al. Prevalência de patógeno bacteriano e susceptibilidade aos antimicrobianos em infecções do trato urinário de amostras ambulatoriais. Rev Bras Anal Clin. 41(1): 87-9, 2009.

3. Vincent CR, Thomas TL, Reyes L, White CL, Canales BK, Brown MB. Symptoms and risk factors associated with first urinary tract infection in college age women: A prospective cohort study. J Urol., 189(3): 904- 10, 2013.

4. Rangel M, Tressa Y, Zago SS. Infecção urinária: do diagnóstico ao tratamento. Colloquium Vitae, jan/jun 2013 5(1): 59-67. 5. Nangino GO, Oliveira CD, Correia PC, Machado NM, Dias AT. Impacto financeiro das infecções nosocomiais em unidades de terapia intensiva em hospital filantrópico de Minas Gerais. Rev Bras Ter Intensiva. 2012; 24(4):357-361.

6. Palou J, Pigrau C, Molina I, Ledesma JM, Angulo J. Etiology and sensitivity of uropathogens identified in uncomplicated lower urinary tract infections in women (ARESC Study): Implications on empiric therapy. Med. Clin. (Barc.). 136(1): 16-7, 2011.

7. Improvement and Management Subcommittee on Urinary Tract Infection Steering Committee on Quality. Management of the initial UTI in febrile infants and children 2 to 24 months. Pediatrics.128:595 e610. 2011.

8. Tanu Singhal. Urine analysis and urine culture: Revisited. Pediatr Infect Dis. 4(4): 178-82, 2012.

9. Silvia CHPM; Protocolos de Microbiologia Clínica, parte 3 - Urocultura. 88 ed., editora News Lab. Vila Velha. 2008.

10. Muller EV, Santos DF, Corrêa NAB. Prevalência de Microrganismos em Infecções do Trato Urinário de Pacientes atendidos no laboratório de análises clínicas da Universidade Paranaense - Umuarama - PR. Rev Bras Anal Clin. 40 (1): 35-7, 2008.

11. Ramos TZ, Pizzolitto EL, Pizzolitto AC. Uso de Teste com Cloridrato de Trifenil Tetrazólio (CTT) para detecção de bacteriúria sintomática e assintomática. Rev Bras Anal Clin. 2006; 38 (3): 197-99.

12. Hömer R, Kocourek GED, Domingue VO, Rigatti F, Bertoncheli CM, Paraginski GL. Comparação de Método de Triagem para Detecção de Bacteriúria em Amostra do Bairro Maringá e do Hospital Universitário de Santa Maria. Saúde, Santa Maria. 2008; 34 a, (1-2): 16-21. 
13. Vieira JMS, Saraiva RMC, Mendonça LCV, Fernandes VO, Pinto MRC, Vieira ABR. Suscetibilidade Antimicrobiana de Bactérias Isoladas de Infecção do Trato Urinário de Pacientes atendidos no Hospital Universitário de Bettina Ferro de Souza, Belém-PA. Rev Bras Anal Clin. 2007; 39 (2): 119 a 121.

14. Costa LC, Belém LF, Silva PMF, Pereira HS, Silvia Júnior ED, Leite TR, et al., Infecções Urinárias em Pacientes Ambulatoriais: Prevalência e Perfil de resistência aos antimicrobianos. Rev Bras Anal Clin. 42 (3): 175-80, 2010.

15. SEMENIUK, H.; CHURCH, D. Evaluation of the leukocyte esterase and nitrite urine dipstick screening tests for detection of bacteriuria in women with suspected uncomplicated urinary tract infections. J Clin Microbiol. 37(9):3051-2, 1999.

16. Sato AF; Svidzinski AE; Consolaro MEL; Boer CG. Nitrito urinário e infecção do trato urinário por cocos gram-positivos Urinary nitrite and urinary-tract infection by gram-positive cocci J Bras Patol Med Lab 41(6):397-404,2005.

17. Souza LF. Prevalência de infecção do trato urinário em pacientes atendidos no Hospital Universitário Alcides Carneiro no período de janeiro a junho de 2013. 45f. Trabalho de Conclusão de Curso (Graduação em Farmácia) - Universidade Estadual da Paraíba, Campina Grande, 2013.

18. Lopes HV, Tavares W. Diagnóstico das infecções do trato urinário. Rev Assoc Med Bras. 51(6): 306-8, 2005.

19. Moura LB, Fernandes MG. A incidência de infecções urinárias causadas por E. coli. Rev Olhar Científico - Faculdades Associadas de Ariquemes. 1(2): 411-25, 2010.

20. Braoios A, Turatti TF; Meredija LCS, Campos TRS, Denadai FHM. Infecções do trato urinário em pacientes não hospitalizados: etiologia e padrão de resistência aos antimicrobianos. J Bras Patol Med Lab. 45(6): 449-56, 2009.

21. Corrêa LA, Canalini AF, Matheus WE. Etiologia das infecções do trato urinário. Int Braz J Urol. 29: 7-10, 2003.

22. Roriz-Filho JS, Vilar FC, Mota LM, Leal CL, Pisi PCB. Infecção do Trato Urinário. Medicina (Ribeirão Preto).43(2): 118-25, 2010.

23. Rocha LCA, Carvalhal GF, Monti PR. Exames complementares na infecção do trato urinário. Int. Braz J. Urol. 29: 15-20, 2003.

24. Costal LC, Belém LF, Silva PMF, Pereira, HS, Silva Junior, ED, Leite TR, et al. Infecções urinárias em pacientes ambulatoriais: prevalência e perfil de resistência aos antimicrobianos. Rev Bras Anal Clin. 42(3): 175 - 80, 2010.

25. Martinelli R, Rocha H. Infecção do trato urinário. In: RIELLA, M. C. (Org.). Princípios de Nefrologia e Distúrbios Hidroeletrolíticos, 4. ed. Rio de Janeiro: Guanabara Koogan, p. 490-506, 2003.

26. Yoshida CS, Irie MMT, Pádua RAF, Boer CG, Siquiera VLD, Consolaro MEL. Análise do desempenho da prova de nitritos das tiras reativas de urina para triagem de infecção bacteriana do trato urinario. Rev Bras Anal Clin. 38(4):255-58, 2006.

27. Ávila MLS. Diagnóstico Laboratorial das principais Doenças infecciosas e Auto-Imunes. $2^{a}$ edição - Rio de Janeiro: Guanabara Koogan, 2011.

28. Sobestiansky J, Centenaro F, Mores JT, Marques PPFMB, Barcellos NSED. Uso de Perfis Sorológicos e Bacteriológicos em Suinocultura. Acta Sci Vet. 37:117-28, 2009.

29. Sato AF, Svidzinski AE, Consolaro MEL, Boer CG. Nitrito urinário e infecção do trato urinário por cocos gram-positivos. J Bras Patol Med Laboratorial. 41:397-404, 2005.

30. Richard RC. Diagnóstico de Laboratório Aplicações Clínicas dos Laboratórios. 6 a edição - Rio de Janeiro; Guanabara Koogan, 2009.

31. Mundt LA, Shanahan K. Exame de urina e de fluidos corporais de Graff. 2 ed. Porto Alegre: Editora Artmed, 2012.

32. Strasinger SK, DI Lorenzo MS. Urinálise e Fluídos Corporais. 5 ed. São Paulo: Editora LMP - Livraria Médica Paulista, 2009. 33. Neto OMV. Infecção do trato Urinário. Simpósio- Urgências e Emergências Infecciosas. 36:365-369. Capítulo IV. Simpósio FRMP, Ribeirão Preto: abr/dez, 2003. 


\section{Lenir Alves Bortolotto}

Endereço para correspondência - Rua: Av. das Torres, $n^{\circ} 500$, Bairro: Loteamento FAG, CEP: 85806-095, Cascavel, PR, Brasil.

E-mail: lenirasb@gmail.com

Denise Michelle Indras - deniseindras@yahoo.com.br

Claudinei Mesquita da Silva - claudineifarmaceutico@hotmail.com

Leyde Daiane de Peder - leydepeder@yahoo.com.br

Enviado em 20 de janeiro de 2016. Aceito em 30 de agosto de 2016. 